

EDUFU

\title{
Teatro-Fórum \\ uma pedagogia da intervenção e outros diálogos possíveis
}

\author{
Antonia Pereira Bezerra
}

\section{SciELO Books / SciELO Livros / SciELO Libros}

BEZERRA, A.P. Teatro-Fórum: uma pedagogia da intervenção e outros diálogos possíveis. In: FLORENTINO, A., and TELLES, N., eds. Cartografias do ensino do teatro [online]. Uberlândia: EDUFU, 2008, pp. 17-28. ISBN 978-85-7078-518-3. https://doi.org/10.7476/9788570785183.0003.

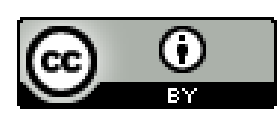

All the contents of this work, except where otherwise noted, is licensed under a Creative Commons Attribution 4.0 International license.

Todo o conteúdo deste trabalho, exceto quando houver ressalva, é publicado sob a licença Creative Commons Atribição $\underline{4.0}$.

Todo el contenido de esta obra, excepto donde se indique lo contrario, está bajo licencia de la licencia $\underline{\text { Creative Commons }}$ Reconocimento 4.0. 


\section{TEATRO-FÓRUM: UMA PEDAGOGIA DA \\ INTERVENÇÃO E OUTROS DIÁLOGOS POSSÍVEIS}

Antonia Pereira Bezerra

Em julho de 2004, no âmbito do Programa Institucional de Bolsas de Iniciação Científica, Pibic/CNPQ, ficou em cartaz na Sala 5 da Escola de Teatro da Universidade Federal da Bahia, UFBA, o espetáculo teatral Um dia na vida de uma enfermeira ou o porquê dos animais domésticos?, texto de Armand Gatti (França, 1970 - tradução nossa). Este espetáculo constituía o resultado prático do projeto de pesquisa intitulado $O$ papel do espectador-ator, da pessoa e da personagem nas poéticas de Augusto Boal e Armand Gatti.

A metodologia da encenação consistia na elaboração de um espetáculo de teatro-fórum, técnica emblemática do Teatro do Oprimido, ancorando-se, dramaturgicamente, nas peças didáticas do Pequeno manual de guerrilha urbana ${ }^{1}$, projeto político-pedagógico de Armand Gatti, o qual comporta, entre outras, a peça supracitada. Nosso interesse principal concentrou-se no exame da inserção/participação do espectador no fenômeno da representação teatral, interrogando o papel/desempenho desse espectador-ator, dessa pessoa-personagem no espetáculo. Essa pesquisa compreendeu, a priori, três etapas estruturadas em torno de uma problemática que considerou:

- a relação ao engajamento político;

- a relação pedagógica: "educação e liberação do espectador-pessoa";

- e, finalmente, os questionamentos sobre as preocupações estéticas: teatro de ação, improvisação e perfeição artística são compatíveis? Toda palavra somente porque autêntica e portadora de uma reivindicação legítima, merece ser encenada?

Foi nesta perspectiva que escolhemos interrogar, no crivo da atualidade, uma técnica e um texto teatral oriundos de poéticas historicamente datadas: O Teatro-Fórum e $\mathrm{O}$ pequeno manual de guerrilha urbana. Antes de expor detalhadamente as bases de nossa hermenêutica e nossa problemática, convém efetuarmos uma breve apresentação dos autores e seus respectivos projetos.

\footnotetext{
1 Após os acontecimentos de maio de 1968, inspirando-se em Che Guevara, Gatti publica Le Petit manuel de guérilla urbaine.
} 


\section{Armand Gatti e Um dia na vida de uma enfermeira}

Para Armand Gatti², diretor de teatro, o mais importante é a relação ao espetáculo e não o espetáculo em si: a obra só passa a ter sentido na medida em que exerce uma ação. Gatti quer agitar o público, "levar aos espíritos um certo número de elementos susceptíveis de fomentar atitudes”. Seguindo essa lógica, após os eventos de maio de 68 e a exemplo de Che Guevara, Gatti publica em 1969 o Pequeno manual de guerrilha urbana ${ }^{4}$ composto de uma série de mini-peças, as quais compreendem um número reduzido de papéis (de um a sete), não necessitando nem do lugar teatral convencional nem de orçamento importante, sendo, por conseguinte, adaptáveis e transportáveis.

Assim, em 1970, a peça intitulada La journée d'une Infirmière ou les Animaux Domestiques (A jornada de uma enfermeira ou o porquê dos animais domésticos), é representada em "foyers", centros para jovens e em hospitais. Uma única atriz e uma equipe de apoio bastante reduzida são suficientes para a realização desse espetáculo que conta com a participação dos militantes do meio hospitalar, disseminados na platéia, durante cada sessão. Gatti define e resume o objetivo e a essência do espetáculo e da protagonista nestes termos: "para que Louise junte-se ao combate de seus camaradas, é necessário que a estrutura da peça tenha um «defeito», um esboço sabiamente sedimentado, aberto às imagens a serem recebidas e aceitas, com o objetivo de exorcizar a vida (sua vida) profunda que ela castrou”.

\section{Augusto Boal}

Augusto Boal, artista, militante ativo, presidente dos Centros de Teatro do Oprimido - CTO do Rio de Janeiro e Paris, pode variar seu projeto em função dos lugares, das circunstâncias, das pessoas e suas necessidades, mas preserva intactos os objetivos essenciais de sua poética: transformar o espectador, ser passivo e depositário, em ator, em protagonista da ação dramática; nunca se contentar em refletir sobre o passado, mas em preparar o futuro's. Na origem e considerando o contexto latino-americano, a Poética do oprimido investe no combate à dupla opressão (individual e coletiva) exercida no teatro e na sociedade: liberando o espectador da sua condição de espectador, ele poderá se libertar de outras opressões, acredita Boal. Desta premissa, nasce o conceito boaliano de espect-ator. A trajetória de Boal é desenhada pouco a pouco e obedece a uma lógica de criação teatral que se recusa a conceber a arte como isolada da vida. Numa atmosfera de experimentação e controvérsias, Boal cria gradativamente novas técnicas: Dramaturgia Simultânea,

\footnotetext{
2 Sobre a trajetória de Gatti e as peças do Pequeno Manual, remetemos o leitor ao artigo de nossa autoria, intitulado Armand Gatti: informando e formando espectadores-atores. BEZERRA, Antonia Pereira. Armand Gatti: informando e formando espectadores-atores. Sala Preta: Revista do Departamento de Artes Cênicas, São Paulo, n. 2, p. 293-299, 2002.

${ }^{3}$ GOZLAN, Gerard; PAYS, Jean-Louis. Gatti aujourd'bui. Paris: Seuil, 1970. p. 166.

${ }^{4} \mathrm{O}$ título foi voluntariamente escolhido em resposta à acusação do Comissário de polícia Sr. Grimaud que, no dia seguinte às manifestações do 10 de maio de 68, declarou: Nós tivemos que lidar com verdadeiros especialistas da guerrilha urbana (apud GONZLAN; PAYS, 1970, p. 252). ${ }^{5}$ BOAL, Augusto. Jogos para atores e não atores. Rio de Janeiro: Civilização Brasileira, 1998. p. 25.
} 
Teatro Invisivel e Teatro-Fórum ${ }^{6}$. Conhecida como a mais completa e espetacular das técnicas do arsenal, a fórmula/fórum, aliás, debate teatral, transformou-se no standarte do Teatro do oprimido?

\section{O Teatro-Fórum}

Um espetáculo de Teatro-Fórum se decompõe em três partes: um aquecimento para favorecer o contato e aproximação de atores e espectadores presentes, seguido da representação da peça denominada antimodelo e, finalmente, do fórum propriamente dito. Preliminarmente à montagem do espetáculo, a troupe deve efetuar uma pesquisa de campo (caso a opressão seja exterior aos membros do grupo), ou então ela organiza um estágio de sensibilização com o grupo implicado na opressão debatida. Após a representação do antimodelo, o Curinga ${ }^{8}$ expõe brevemente os mecanismos das ações/intervenções que se seguirão. Passando rapidamente da teoria à prática, ele convida os espectadores a "invadirem" a cena para se expressar com o corpo (assimilar algumas posturas, construir imagens a partir de outras), mas também para tomar consciência da sua profunda mecanização. Estes exercícios simples distendem a atmosfera e unem o público presente. A esse ritual segue-se a representação do Antimodelo, peça escrita sob um tema único, a opressão. Após a presentação, a troupe propõe-se a reapresentar a peça. Porém, desta vez, quando um espectador considerar que um dos personagens comete um erro, favorecendo a opressão, ele pode gritar Stop!, entrar em cena para substituir a personagem oprimida e os outros atores irão improvisar com ele a solução proposta. Mas, o jogo não é tão simples! Como na vida real, se a solução do espectador não é viável, ele perde e é devolvido à platéia pelo organizador do jogo, o Curinga.

\section{Nossa experiência}

Em nossa pesquisa, para viabilizar o jogo entre atores e espectadores, foi necessário inverter um pouco a ordem dos fatos. Tendo em vista que a base do nosso antimodelo era o texto Um dia na vida de uma enfermeira, primeiramente fizemos a presentação do espetáculo para, somente em seguida, aquecermos o público pelo viés da técnica do teatro-imagem. Em outras palavras, apenas no final da primeira presentação, construíamos três imagens, que capturavam e retratavam os momentos mais cruciais da opressão debatida e exibíamos ao espectador. Essas imagens eram a única ponte entre a sala e a cena, o único viés entre a ficção e o jogo, o motor da entrada do espectador em cena. $\mathrm{O}$ espectador poderia, se quisesse e quando quisesse, assumir uma ou todas as imagens, usando da palavra ou apenas de gestos, e propor uma solução à opressão de Louise, a enfermeira protagonista ${ }^{9}$.

\footnotetext{
6 Para saber mais sobre o Teatro do Oprimido ver nosso livro Le Théâtre de l'Opprimé et la notion du spectateur-acteur (Genèse personne, personnage, personnalité). BEZERRA, Antonia Pereira. Le théatre de l'opprimé et la notion du spectateur-acteur (Genèse personne, personnage, personnalité). Lille: ANRT, Presses Universitaires de Lille, 2002. 245 p.

7 O Teatro-Fórum nasce na periferia de Lima, Peru, em 1975, mas evolui na Europa.

${ }^{8}$ Inspirado nas técnicas brechtianas, este personagem aparece em Arena conta Tiradentes (Teatro Arena de São Paulo, 1968). Numa sessão de Teatro-Fórum, o Curinga desempenha o papel de mediador do jogo, exegeta e tem uma função maiêutica, pedagógica.

9 Para se ter uma idéia mais concreta e global dos dispositivos dramatúrgicos e técnicas de jogo
} 
No tocante à dramaturgia, em face das características eminentemente épicas do texto de Gatti, tivemos que efetuar uma série de modificações para torná-lo mais dramático e adaptável à técnica do Teatro-Fórum. La Journée d'une Infirmière, por exemplo, era um monólogo que comportava apenas a protagonista, Louise, e no qual acrescentamos mais dois antagonistas, conferindo à trama mais suspense e ação. Em outras palavras, fomos além de uma simples adaptação e reescrevemos a peça, pois para conferir uma dimensão mais dialética ao conflito de Louise, centrado na narração objetiva e crítica, inserimos na trama de Gatti, momentos de intensa subjetivação e objetivação, alternando a solidão de Louise com a invasão dos antagonistas, seus opressores que irrompiam no seu espaço, nas figuras da chefe do hospital (Sra. Kopalewski) e da colega do sindicato (Noune).

Quanto ao resultado final, é evidente que em um mês, e mais algumas apresentações, não encontramos respostas para todas as questões levantadas e que muitas das hipóteses avançadas necessitam, ainda, de um contato mais longo e intenso com o público. Não obstante, no que concerne à participação do espectador, algo nos interpelou profundamente: o espetáculo montado dentro de uma estética realista-naturalista (no que diz respeito à interpretação das atrizes), com uma abordagem épica para a narrativa, os cenários e demais acessórios, intimidava os espectadores. Acentuando deliberadamente o símbolo, a força da convenção teatral, evidenciando as fronteiras que separam o palco da platéia e sem prepararmos previamente o espectador para sua intervenção teatral, nos preocupávamos, essencialmente, em suscitar as intervenções sem abrir mão de uma técnica teatral elaborada, aliada a uma consciência política clara, a fim de evitar a manipulação e o sacrifício do rigor estético em detrimento da militância e do imediatismo que toda e qualquer encenação sobre opressão impõe. Esse foi um grande desafio, uma dimensão pensada ao longo de toda a pesquisa e em todas as apresentações.

Teoricamente, constatamos que o Teatro do Oprimido - a técnica do Teatro-Fórum em particular - aliado à dramaturgia de Gatti, precisamente às peças do Pequeno manual, amplia a problemática do espectador e sua implicação no jogo teatral. Ambos os projetos discutem a dificuldade de ser, ao mesmo tempo, pessoa e personagem, de ocupar, simultaneamente, um espaço de vida e ficção interrogando as poéticas teatrais, a natureza e os fins do jogo teatral. Entretanto, noite após noite, na prática, durante a construção das imagens e diante de um longo e pontual silêncio, como se ninguém pudesse ou quisesse intervir, até que uma mão timidamente se elevasse e uma silhueta saísse da penumbra da platéia e irrompesse o palco iluminado; diante da avalanche de intervenções que se sucediam, vencendo este primeiro momento de pudor, não mais nos colocávamos questões de ordem estética ou política, não mais pensávamos em oprimidos nem opressores strictu sensu. Por alguns instantes, impactados, diante do eterno encanto do teatro, perguntávamo-nos, apenas, como e onde, ao longo da história, já estariam prefiguradas poéticas nas quais o "ator social" desnuda o "ator teatral" e aponta o problema de seus destinos comuns. Remontando o fio da história, em quantos outros gêneros e formas

aplicadas ao espetáculo, ver nosso vídeo sobre ele que está disponível no acervo videográfico da Escola de Teatro/PPGAC da UFBA. 
teatrais os personagens já simularam algumas crises, abandonando a cena e invadindo a vida? Em outras palavras, para além dos objetivos políticos, terapêuticos, onde e como, no túnel do tempo, o Teatro-Fórum e sua ancestral e imanente pedagogia da intervenção já se prefiguravam?

\section{Outros diálogos possíveis ou a gênese do Teatro-Fórum}

Quando de sua chegada à Europa, perguntaram a Boal se era possível aplicar ali as técnicas concebidas e realizadas em resposta - estética e política - à intolerável repressão que se exercia na América Latina. Perplexo, ele hesitou em dizer sim. Atualmente, essa questão não se coloca mais. A prática reafirma que essas técnicas não foram inventadas por alguém, nem para um continente específico, como sempre proclamou o seu autor: o Teatro do Oprimido sempre existiu.

Inúmeras são as trupes e encenadores modernos que, no ocidente, tentaram reencontrar e reafirmar os vestígios das origens, resgatando a pedagogia da intervenção e do lúdico na representação. Se adotarmos o ponto de vista do historiador, nesse sobrevôo desprovido de rigor cronológico, poderíamos dizer que o Teatro-Fórum e sua pedagogia da intervenção já se prefiguravam a partir do momento em que o homem primitivo começou a "representar" seu medo, suas angústias e suas obsessões a fim de exorcizá-los. Quando evocamos o fenômeno da representação e sua “origem”, o que nos vem ao espírito é, indubitavelmente, a imagem do homem pré-histórico acreditando poder controlar, domar os animais recriando-os, representando-os, com sua mão pensante ${ }^{10}$. Remetemo-nos, igualmente, às danças xamânicas, aos jeux da Idade Média - os mistérios e milagres, os laudus - com suas incidências políticas e sociológicas consideráveis. Certamente, tal viagem no tempo ultrapassa o alcance deste trabalho, mas não nos impede de sobrevoar até a metade do século XVI ${ }^{11}$, até à Commedia dell'arte, por exemplo.

\section{A Commedia dell'arte}

Esse gênero teatral fecundou dois séculos de civilização européia e modelou as formas teatrais mais reconhecidas como o teatro de Shakespeare ou de Molière. Seus traços principais - a improvisação, os personagens fixos, a espontaneidade - privilegiam $\mathrm{o}$ ator e o texto e não a personagem. Assim, pela utilização que se faz, neste gênero, da espontaneidade a partir de cannovaccios preestabelecidos, ousamos aproximar o Teatro-Fórum da Commedia dell'arte. Com efeito, esta como aquele levantam e, de certa maneira, simplificam o paradoxo do comediante. Mas, ao contrário do Teatro-Fórum, se a Commedia dell'arte permite a $a b$-reação ${ }^{12}$, paralelamente ela não conduz o espectador ao distanciamento; se ela oferece ao público um espelho, não o autoriza, todavia, a

${ }^{10}$ Claude Lévi-Strauss, Michel Leiris, Roger Bastide e Sigmund Freud, entre outros, contribuíram para o esclarecimento desta questão.

${ }_{11}$ Mesmo se ousamos infringir a cronologia da "história do fenômeno da representação, em geral, e da representação teatral, em particular”.

${ }_{12}$ Psicanálise: descarga emocional mais ou menos intensa, em que o indivíduo revive um acontecimento traumático que o libera da repressão à qual estava submetido e que pode ser espontânea ou manifestar-se no curso de certos processos psicoterápicos, por ação deles. PSICANÁLISE. In: FERREIRA, Aurélio Buarque de Holanda. Novo dicionário Aurélio de língua portuguesa. 2. ed. rev. e ampl. Rio de Janeiro: Nova Fronteira, 1986. p. 13. 
tornar-se o outro - o personagem ativo (o ator), mas apenas ele mesmo, a pessoa passiva (o espectador). A Commedia dell'arte se contenta em oferecer um rico e "belo arsenal" de máscaras, de espelhos e disfarces. Se quatro séculos mais tarde a representação se pretende o duplo da vida, como desejou Artaud em seu projeto visionário, atualmente, no Teatro do Oprimido, ela pretende desfazer-se de todo um revestimento anacrônico para tornar-se a própria vida. Boal sustenta, com efeito, que o Teatro-Fórum, em particular, é um meio "muito mais rico que uma assembléia" onde acontece, freqüentemente, que se digam coisas como se diriam muitas outras.

\section{O teatro shakespeariano: Hamlet (v. 1600)}

As representações do Antimodelo e seus aspectos pedagógicos comportam, igualmente, algumas analogias com o teatro shakespeariano. Em Hamlet, por exemplo, é feita uma magistral utilização da ab-reacção, pelos jogos de reflexos e de espelhos. O desejo de "desalienar-se" desencadeia não somente uma busca pela verdade, mas também por alternativas de comportamento face à situação conflituosa que se representa. Sem querer reforçar o clima "freudiano", que muitos críticos acreditam discernir nas grandes tragédias shakespearianas, pensamos que Hamlet é mais que "teatro no teatro". A exemplo de Sonbo de uma noite de verão (v. 1595), essa peça recria uma atmosfera atravessada pela agulha das paixões humanas, portadora de todas as possibilidades de interpretação, de esclarecimento e, até mesmo, de (re)utilizações. Não é por acaso se cada época soube encontrar em Hamlet referências a sua própria história. A peça dentro da peça poderia ser lida como um Teatro-Fórum onde o "Curinga Hamlet" vigia e dirige o jogo, sob os traços de um espectador dissimulado na sala, inquirindo, "jogando verde para colber maduro".

O personagem de Hamlet aborda a questão da primazia do papel, onde a catarse do espectador religa-se a do ator. Mas, notemos que a catarse que se opera aqui, a da "grande peça", distancia-se da noção boaliana do termo para aproximar-se, a priori, da concepção aristotélica, pois, embora nesta peça uma metalinguagem tenha lugar, além de Claudius, da rainha Gertrude e de Hamlet, os outros espectadores, ignorantes da "situação", permanecem passivos: eco desconcertante com o Teatro-Invisível que Boal, atualmente, hesita em praticar. Além disso, o papel de Hamlet é um papel imposto. Hamlet aceita a situação mesmo revoltando-se contra ela. Tal qual os oprimidos, é constrangido e forçado que desempenha o seu papel. Hamlet busca liberar-se da opressão porque ele é outro além da personagem, ele a ultrapassa. O Teatro-Fórum não reivindica esse desenvolvimento do indivíduo pelo viés do personagem que se realiza na direção que lhe é própria? Reavaliar-se no Teatro-Fórum significa tornar-se a si mesmo, confrontar-se à sua identidade humana profunda pela mediação do drama, da opressão vivida e representada.

Essa peça dentro da peça poderia ser um fórum onde Hamlet, o Curinga, vigiaria as verdadeiras ações de seu tio, o rei fratricida, incapaz de suportar a representação de seu crime. Um fórum onde, graças ao teatro, procura-se a verdade e a liberação. Se Hamlet está dividido entre ser e não ser, os protagonistas do Antimodelo, esses “personagens” com “personalidades” diferentes, podem 
- uma vez que a representação e diante das alternativas a suas questões - decidir fugir, acomodar-se ou lutar. Não é depois da representação, pela voz do real e não pela voz, talvez enganadora, de um fantasma, que Hamlet sabe onde se encontra a verdade? Por outro lado, é preciso admitir que ele cai numa nova armadilha; a partir daí, ele se impõe um outro papel: o do justiceiro, para quem é tarde demais para renunciar. Mas, toda pedagogia da intervenção não pressupõe uma implicação?

\section{Luigi Pirandello (1867 - 1936)}

Sempre nesse espírito de busca por uma "prefiguração" do Teatro-Fórum e sua pedagogia da intervenção, como não pensar em Luigi Pirandello, em seu teatro de máscaras e reflexos? Como não pensar nessa exploração das profundezas de identidades telescopicamente examinadas e nesse questionamento não somente da noção de barreira entre o palco e a platéia, mas também das noções de realidade e ficção? Seis personagens a procura de um autor nos parece mostrar que o teatro é que é verdade e o travestimento, nudez; que a máscara, no sentido etimológico do termo, é que é real. Pirandello nos mostra que os verdadeiros vivos de sua peça são personagens aparentemente irreais, que questionam a identidade e a presença carnal dos chamados vivos. Entretanto, ao examinar mais de perto, esses personagens recusam o monopólio dos atores de carne e sangue que representam a peça de um certo Pirandello, num certo teatro, diante de um certo público. Eles reivindicam, assim, o direito à existência. Isso nos remete, de certa maneira, às disputas (estéticas e políticas) entre oprimidos-artistas e atores profissionais.

Moderamos, pois, a comparação, uma vez que o teatro de Pirandello, se não aborda a questão da "loucura" diretamente, no mínimo, alude com freqüência aos jogos de espelhos da loucura. É provável que o drama familiar de Pirandello, a "doença” de sua mulher Antonietta esteja na origem do lugar atribuído à loucura em suas obras. $\mathrm{O}$ jogo constante entre o real e a aparência impregna suas peças de uma dialética cortante e patética do ser e do parecer. Isso é, particularmente, impactante em Henrique IV (representada pela primeira vez em 1925). Ressalte-se, também, que a maior parte das peças de Pirandello foi concebida para ser representada de maneira convencional, mesmo se, às vezes, os atores invadem a sala e convidam os espectadores a subir no palco, a exemplo de Assim (Assado), representada pela primeira vez em $1926^{13}$. Enfim, sua trajetória de homem não testemunha de nenhuma rejeição à instituição teatral.

Em Seis personagens a procura de um autor, quando o Pai reage contra a intolerância do Diretor, o qual se recusa a acreditar que está, realmente, diante de personagens, cujos dramas da vida imaginária permanecem inacabados, confissões em aparência patéticas, mas, na verdade profundas, jorram:

\footnotetext{
${ }_{13}$ Nessa peça, uma trupe representa o drama verdadeiro de uma atriz decadente (La Mareno, a qual se encontra na sala). Indignada, ela ameaça entrar em cena, mas seu marido a contém. No entreato, ela decide ir às coxias invectivar a trupe e, particularmente, a atriz que representa seu papel. Isso lembra um Fórum relatado por Boal, em Jogos para atores e não atores, ocorrido em 1980, em Grodano (povoado da Sicília), onde o prefeito, tomado de cólera diante do ator que representa seu papel (é um opressor, se é preciso esclarecer) e, não se contendo, mais grita Stop!, entra em cena e representa ele próprio.
} 
[...] o senhor diz que não tem tempo a perder com loucos e, no entanto, ninguém melhor que o senhor pode saber que a natureza se serve da imaginação humana para continuar num plano mais elevado seu trabalho de criação ${ }^{14}$.

Apesar da sinceridade desses propósitos, o Diretor e a trupe dos "verdadeiros atores" não consegue escapar de julgar a situação absurda e inverossímil. Numerosas são as sessões do Teatro-Fórum em que, quando o Curinga (duplo de Boal) grita Stop é mágico!, os espec(atores), indignados, recusam-se a deixar a cena, persuadidos de que suas proposições, julgadas "ilusórias" pelo diretor do jogo, são perfeitamente realistas e aplicáveis.

Também os cannovaccios do Antimodelo, qualificados de inferiores em relação à “dramaturgia clássica e dominante”, remetem à cena em que o Diretor pergunta aos seis personagens onde está o manuscrito de suas vidas. O Pai (duplo de Pirandello), vítima das zombarias dos "verdadeiros atores", replica: "Ele está em nós, senhor Diretor. O drama está em nós; nós somos o drama e estamos impacientes para representá-lo, como nos impele a paixão que ferve em nós!”. Assim, eles reivindicam que seus papéis sejam representados por eles e não pela trupe profissional que se "recusa" a deixar o palco. Não poderíamos encontrar eco mais justo para (re) evocar os desacertos dos espect(atores), em suas improvisações na cena "sagrada" do teatro. E, mais particularmente, no que concerne à intensidade emotiva que revira toda sessão do Teatro do Oprimido. Como Pirandello com seus "personagens", Boal não cessa de clamar às "pessoas": "Deixemos os oprimidos se exprimir, porque somente eles podem nos mostrar onde está a opressão"15. Esse descomprometido sobrevôo nos leva a uma outra interrogação importante.

\section{A representação e o sagrado: outra vez o lúdico, outra vez a pedagógica da intervenção}

Há uma idéia muito difundida de que a noção de sagrado, na representação em geral, está estritamente ligada à história do homem, posto que ela aparece nas danças xamânicas (ou ainda nas danças rituais dos Orixás no Brasil), mas também nas pinturas rupestres ${ }^{16}$. Do mesmo modo, a reencontramos na teatralidade dos cultos de possessão ou da representação - o que é dado em espetáculo, o que reatualiza o mito permitindo o exorcismo e sucessivo estabelecimento e quebra da magia. Quer consideremos as danças xamânicas, o vodu haitiano, as danças de possessão dos Sonrhais do Niger e mesmo os Mestres loucos, do filme etnográfico de Jean Rouch ${ }^{17}$ - do qual Jean Genet tiraria sua obra prima Les Nègres, em 1958 - o tempo parece ter sofrido uma espécie de curto-circuito; ou, talvez, seja a prova da unicidade do homem, idêntico a si mesmo para além dos milênios. Tanto no homem da pré-história, quanto em nossos contemporâneos,

\footnotetext{
${ }_{14}$ PIRANDELLO, Luigi. Six personnages en quête d'auteur (suivi de Chacun sa vérité, Henri IV, Comme ci (ou comme ça). Paris: Gallimard, 1950. p. 17.

${ }^{15}$ BOAL, Augusto. Stop! C'est magique. Paris: L'Échappée Belle/Hachette Littérature, 1980. p. 22.

${ }_{16}$ Sobre o tema, consultar MARINGE, Jean. L'homme préhistorique et es Dieux. Paris: Arthaud, 1958.

17 Filmado em 1955 no subúrbio de Accra, em Gana (que se chamava, então, Gold Coast), esse filme recebeu o primeiro prêmio entre os filmes etnográficos, geográficos, turísticos e folclóricos, no "Festival Internacional de Veneza", em 1957. Falaremos mais tarde de sua temática.
} 
submetidos à aceleração aparente da história, reencontramos as mesmas preocupações essenciais, a mesma tentativa de dominar as situações pela representação, seja com relação a Deus - pelo viés do sagrado -, seja com relação à condição de dependência aos fatos.

E em quaisquer das situações, o lúdico e a pedagogia da intervenção se configuram como uma via privilegiada para se atingir os fins, de sorte que, também nesse domínio, a busca por "controle”, que passa pela representação, poderia ser vista como uma sorte de eco longínquo da Poética do Oprimido, do Teatro-Fórum, notadamente em seu drama/debate que, pretendendo liberar o homem de uma opressão vivida, incita a pessoa a "transgredir" os limites de sua personalidade, pela metamorfose do espectador em personagem. Não obstante, precisamos relativizar a noção de rito e levar em consideração o conteúdo diferencial, ainda que o mimetismo identificado nos "rituais de possessão" como uma constante - "posto que posso me tornar você, eu te domino" - é, de certa maneira, uma das buscas do teatro. Um dos postulados fundamentais da Poética do Oprimido não é a "ficção antes da realidade", ou seja: "posto que posso representar minha libertação, posso realizá-la em seguida na vida?”

\section{Os mestres loucos}

Para aprofundar essa questão, evocaremos Os mestres loucos, filme que nos mostra uma cerimônia sacrificial entre os africanos do subúrbio de Accra (capital de Gana). Habitantes do vilarejo da etnia Haouka transformam-se em possuídos: um cão é degolado (nesse momento, os iniciados bebem seu sangue), depois esquartejado e comido. Além da dança e do transe, podemos interrogar-nos como o cineasta, por que comer um cão? Posto que se trata de uma carne totalmente proibida, os Haoukas pensam que ao ingeri-la serão mais poderosos que todos os outros homens, negros ou brancos.

O filme de Jean Rouch remete não somente aos rituais do sacrifício grego do bode, mas também à refeição totêmica freudiana, o mito dos irmãos cassados que matam e comem o pai, o ancestral do grupo, o espírito protetor. Transgredindo a ordem das coisas, do sagrado consagrado, eles se tornam tabus. Ora “ [...] o tabu é um ato proibido, em cuja direção o inconsciente inclina-se com uma tendência muito forte"18. Essa questão concerne não somente o teatro, mas também todo um ramo médico e político. Em Magia e religião, Claude Lévi-Strauss parte do princípio que "eficácia simbólica, cura xamânica e cura psicanalítica são reorganizações estruturais entre corpo e psiquismo". A esse respeito basta escutar a voz em off de J. Rouch para se convencer:

[...] quando o sacrifício é cometido, o inconsciente é liberado; os mitos podem entrar em ação. E desses OPRIMIDOS, livres dos limites, a chaga do medo jorra à luz dia: o mais constrangedor de seus mitos, a imagem de seus OPRESSORES, eles encarnam a imagem incoerente, incompreensível, que se fazem dos branco, poderosos e diferentes até parecerem desumanos.

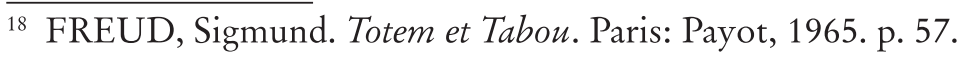


Não se trata aqui de procurar saber se os "possuídos" fingem ou, ainda, de diagnosticar a possessão. Se é verdade que o possuído alcança um estado que põe em jogo a totalidade de seu ser, poderíamos, então, perguntar-nos se o teatro, como a possessão, não seria uma busca por "remédios" para "curar a vida"? Ora, na manhã seguinte ao ritual, Jean Rouch vai reencontrar os Haoukas - com sua câmera - não mais na floresta, mas na cidade, cada um em seu papel, sua função social habitual. Diante de seus rostos sorridentes e seus comportamentos "pacíficos", o autor se pergunta "se esses homens da África não conhecem certos remédios que lhes permitem, por uma via incomum, integrarem-se perfeitamente a seu meio [...] Remédios que nós os ocidentais não conhecemos ainda”.

\section{Antonin Artaud}

Em busca de remédios para curar a vida, a exemplo de Freud, mas ao contrário de Brecht que concebia o poder ideológico apenas como uma potência "exteriora", Artaud, em sua inquietante trajetória, também sabia que o nosso "ser profundo" é infectado por monstros, por todo um conjunto de pulsões destruidoras acumuladas em nós desde a infância. Porém, Artaud jamais pôde praticar seu teatro. Suas aplicações teóricas conheceram o fracasso, suas peças não tiveram repercussão nem na França nem alhures ${ }^{19}$. Les Cenci foi "um desastre financeiro" (somente dezessete representações), ainda que, para ele, tenha sido "um sucesso no absoluto"20. A breve aventura do teatro Alfred Jarry $(1926$ - 1930) faz nascer no plano teórico - e com furor - aquela do teatro e seu duplo: poesia, loucura, filosofia e profecias dialogam de maneira extraordinária. Em 1935, o autor parte para o México, país dos Tarahumaras, em busca do mana. Mas, as montanhas mexicanas, gravadas com corpos de homens esculpidos como sinais na rocha, já rondavam o imaginário de Artaud desde 1933, ano em que inicia suas pesquisas sobre Héliogabale ou o anarquista coroado. Em 1934, ele publica um primeiro ensaio, El Gabal - encarnação do mito hermafrodita adorador do sol e da pedra negra ELAGABALE: "Esse Deus ELAGABALUS, ou saído da montanha, cume brilhante, vem de muito longe"21.

\section{Considerações conclusivas: o fim do começo}

Se as noções de jogo, de opressão e de intervenção concernem tanto o teatro, a psicologia, quanto a política e a educação, a necessidade de diálogos como estes que estabelecemos ao longo deste ensaio torna-se imprescindível, sobretudo pelo fato da técnica aqui analisada trabalhar, dialeticamente, com todas essas noções. Ora o Teatro-Fórum é uma pedagogia da e pela intervenção teatral. Assim, interrogamo-nos, ainda, enquanto professora e pesquisadora: o que ensejamos precisamente? Fazer dos estudantes melhores espectadores, amadores esclarecidos e mais exigentes ou transformá-los igualmente em «atores»? Será necessário então iniciá-los numa arte concebida como separada da vida? Teremos que engajá-los em montagens de espetáculos, levando-os a preservar, paralelamente, a ruptura entre

19 Notadamente Ventre brulé ou la mére folle (1926), Les Cenci (1930) adaptada de Shelley, dirigida e representada pelo próprio Artaud.

${ }^{20}$ ARTAUD, Antonin. Le théatre et son double. Paris: Payot, 1960. p. 10.

21 ARTAUD, Antonin. Héliogabale ou l'anarchiste couronné. Paris: Gallimard, 1979. p. 17. 
mimesis e criação nos seus comportamentos sociais? Ou será questão de ensinar-lhes, de uma só vez, que o teatro é uma dimensão substancial do ser humano, o Solar e o Lunar, Apolo e Dionísio, a clareza de espírito e as profundezas noturnas do ser? Não se trata, aqui, de estabelecer um equilíbrio estático entre Apolo e Dionisio ou, para retomar as oposições binárias, de colocar um pouco de "papel» e um pouco de "personalidade", um pouco de Brecht, um pouco de Artaud, sob pena de confundir dois enfoques absolutamente distintos: o da arte e o da vida cotidiana. Seguir quem acredita que "o homem-espectador" pode ser o criador e mestre do destino do "homem-personagem", quem clama como Boal "Não digam! Venham em cena e mostrem-nos suas visões do mundo"22, ou quem prefere, como Gatti, ir ao encontro dos "atores da realidade" e reapropriar-se com eles do "poder da linguagem teatral" para se tornarem "criadores" seria uma opção eficaz? A dimensão prática desse projeto respondeu a muitas dessas importantes questões.

$\overline{22}$ BOAL, 1980, p. 50. 


\section{REFERÊNCIAS}

ARTAUD, Antonin. Héliogabale ou l'anarchiste couronné. Paris: Gallimard, 1979.

ARTAUD, Antonin. Le théâtre et son double. Paris: Payot, 1960.

BEZERRA, Antonia Pereira. Armand Gatti: informando e formando espectadores-atores. Sala Preta: Revista do Departamento de Artes Cênicas, São Paulo, n. 2, p. 293-299, 2002.

BEZERRA, Antonia Pereira. Le théâtre de l'opprimé et la notion du spectateur-acteur (Genèse personne, personnage, personnalité). Lille: ANRT, Presses Universitaires de Lille, 2002.

BOAL, Augusto. Jogos para atores e não atores. Rio de Janeiro: Civilização Brasileira, 1998.

BOAL, Augusto. Stop! C'est magique. Paris: L’Échappée Belle/Hachette Littérature, 1980.

BOAL, Augusto. Teatro do oprimido e outras poéticas políticas, Rio de Janeiro: Civilização Brasileira, 1988.

FREUD, Sigmund. Totem et Tabou. Paris: Payot, 1965.

GATTI, Armand. Théâtre complet. Paris: Verdier Lagrasse, 1970. 3 t.

GOZLAN, Gerard; PAYS, Jean-Louis. Gatti aujourd'bui. Paris: Seuil, 1970.

LÉVI-STRAUSS, Claude. Antropologia estrutural. Paris: Plon, 1958.

MARINGE, Jean. L’homme préhistorique et es Dieux. Paris: Arthaud, 1958.

MANNONI, Octave. Les clefs pour l'imaginaire. Paris: Seuil, 1980.

PIRANDELLO, Luigi. Six personnages en quête d'auteur (suivi de Chacun sa vérité, Henri IV, Comme ci (ou comme ça). Paris: Gallimard, 1950.

PSICANÁLISE. In: FERREIRA, Aurélio Buarque de Holanda. Novo dicionário Aurélio de lingua portuguesa. 2. ed. rev. e ampl. Rio de Janeiro: Nova Fronteira, 1986.

ROUCH, Jean. Lês maîtres fous. Paris: Cinémathèque, 1953. 